\title{
Gastroözefageal reflü hastalığı ile diş çürümesi arasındaki ilişki
}

\author{
The relationship between gastroesophageal reflux disease and tooth decay?
}

Buğra ÖZKAN ${ }^{1}$, Levent FILIK², Osman SAĞLAM ${ }^{1}$

Ankara Eğitim ve Araştırma Hastanesi ${ }^{1}{ }_{1}$ Ç Hastalılan Kliniğ̈i, ${ }^{2}$ Gastroenteroloji Kliniği, Ankara

\begin{abstract}
Giriş ve Amaç: Bu çalışmanın amacı gastroözefageal reflü hastalığı ile diş çürüğü arasındaki iliş̧kiyi göstermektir. Diş çürüklerinin en sık sebebinin zayıf ağız hijyeni olduğu bilinmektedir. Gastrik içeriğin ağza gelmesi de zayıf ağız hijyenine, dental erozyonlara ve diş çürüklerine sebep olabilir. Bu çalışmada gastroözefageal reflü hastalığının diş çürügüune neden olup olmadığı araștırılmıştır. Gereç ve Yöntem: Altmışbeş hasta çalışmaya dahil edildi. Otuz hastada gastroözefageal reflü hastalığı bulundu. Gastroözefageal reflü hastalığı tanı doğrulaması endoskopi bulgularnna göre yapıldı. Otuz iki hastada diș çürüğü bulundu. Bulgular: Gastroözefageal reflü hastalığı ile diș çürüğü arasında ilişki bulunmadı. Çalışmamızda gastroözefageal reflü hastalarında diş çürügüu, reflüsü olmayanlar ile yakın bulunmuştur. Sonuç: Diş çürüğü ile kuvvetli ilişkisi olanın diş firçalama ve mekanik temizlik olduğu anlaşılmaktadır. Reflü tedavisi verilmesi sırasında hastalara diş fırçalaması gerektiği ısrarla hatırlatılmalıdır.
\end{abstract}

Anahtar kelimeler: Diş çürümesi, gastroözefageal reflü hastalı̆̆ı, dental erozyon

\section{GIIRISS}

Gastroözefageal reflü fizyolojik bir tablo olmakla birlikte; gastroözefagal reflü hastalığı (GÖRH) patolojik bir durumu yansıtır. Gastroenteroloji polikliniğine önemli oranda başvuru nedenidir. Mortalitesi düşük olsa da görülme sıklığında artıs, uzun süren semptomlar, yaşam kalitesini etkilemesi ve sosyal sağlık sistemine getirdiği ek maliyet nedeniyle önemli bir hastalıktır.

GÖRH'nın ağız ve diş bulguları çoğu zaman hasta ve hekim tarafindan göz ardı edilir. Ağız ve diş bulguları bu nedenle tablo kötüleşene kadar tedavisiz kalmaktadır. Oral mukozada kaşıntı ve yanma, diş hassasiyeti, aft, ekşi tat, dişte erozyona kadar giden bulgular birçok çalışmada GÖRH ile ilişkili bulunmuştur. Doğrudan diş çürüğü ile ilgili bulgular çelişkili olsa da GÖRH'nın diş kaybını artırıcı bir etkisi olduğu mümkün görülmektedir.

\section{GEREÇ VE YÖNTEM}

Bu çalışmaya 2014 yılı Kasım ayında Ankara Eğitim ve Araştırma Hastanesi Gastroenteroloji polikliniğine dispepsi şikayeti ile başvuran ve üst gastrointestinal sistem endoskopisi
Backgaround and Aims: The aim of this study was to show the relationship of gastroesophageal reflux disease and tooth decay. The most common cause of tooth decay is poor oral hygiene but gastric contents may also cause poor oral hygiene and tooth decay. In this study, we hypothesized and investigated whether gastroesophageal reflux disease caused tooth decay. Materials and Methods: Sixty-five patients were studied; 30 patients had gastroesophageal reflux disease, with disease diagnosis confirmation achieved by endoscopy. 32 patient had tooth decay. Results: Gastroesophageal reflux disease is not associated with tooth decay. Patients with and without gastroesophageal reflux disease had nearly equal tooth decay. Conclusions: Results from this study did not support the hypothesis that gastroesophageal reflux disease can be a risk factor for tooth decay. The important point is to brush teeth.

Key words: Tooth wear, tooth caries, gastroesophageal reflux disease, saliva, dental erosion

yapılan 18-65 yaş arası hastalar dahil edildi. Endoskopi raporuna göre hastalar GÖRH, ülser gurubu olarak ayrıldı. Hastalara diş firçalama alışkanlıkları soruldu, günde 1 kez ve daha fazla şeklinde cevap verenler diş fırçalama açısından pozitif olarak kabul edildi. Tüm hastalara firçalama sırasında şikayeti olup olmadığı soruldu. Organik bir neden olarak bulantı ve öğürme şikayeti olanlarla olmayanlar ayırt edildi. Tüm hastalar ise aktif çürük açısından değerlendirildi. Son 1 yll içinde diş çürügü olanlar pozitif bulgu olarak kaydedildi.

\section{BULGULAR}

Değerlendirmeye alınan 65 hastanın \%41.5'i (n: 27) erkek, \%58,5'i (n: 38) kadın idi (Tablo 1). Hastaların \%46.1'inde (n: 30) GÖRH pozitif olarak tespit edildi. Hastaların \%87.6'sında (n: 57) gastrit tanısı mevcuttu. Endoskopik olarak ülseri tespit edilenlerin (n: 11) oranı tüm hastaların \%16.9'u idi. Gastroenteroloji polikliniğine başvuran tüm hastaların \%63'ü (n: 41) dişlerini firçaladığını belirtti (Tablo 2). Hastaların \%33.8'sinde (n:22) diş firçalarken bulantı ve öğürme şikayeti oluşmuştu. Tüm hastalar arasında aktif çürük şikayeti olanlar (\%49.2) popülasyonun neredeyse yarısını oluşturuyordu. 
Erkek hastaların \%55,6'sında (n:15) kadın hastaların ise \%44,7'sinde (n:17) aktif çürük bulundu. GÖRH olanlarda çürük oranı \%46.7 (n:14) iken, bu oran GÖRH olmayanlarda \%51.4 (n:18) olarak bulundu (Tablo 3). Gastriti olan hastaların \%45.6'sında (n: 26) çürük pozitif olarak tespit edilirken, gastriti olmayanlarda bu oran \%75 (n: 6) olarak bulundu. Ülser ile çürük arasındaki ilişkiye bakıldığında, ülseri olanların \%54.5'inde (n: 6) çürük pozitif iken, ülseri olmayanların \%48.1'sinde (n: 26) çürük saptandı.

\section{Tablo 1. Demografik veriler}

\begin{tabular}{ll}
\hline Karakteristik & Hastalar (n=65) \\
\hline Yaş & 42.1 (ort) \\
\hline Erkek & $27(\% 41.5)$ \\
\hline Kadın & $38(\% 58.5)$ \\
\hline GÖRH pozitif & $30(\% 46.1)$ \\
\hline Gastrit pozitif & $57(\% 87.6)$ \\
\hline Ülser pozitif & $11(\% 16.9)$ \\
\hline Diş firçalayanlar & $41(\% 63)$ \\
\hline Diş fırçalamada bulantı-öğürme şikayeti olanlar & $22(\% 33.8)$ \\
\hline Aktif çürük & $32(\% 49.2)$
\end{tabular}

Tablo 2. Diş firçalayan ve firçalamayan hastalarda diş çürüğü görülme sıklığı

\begin{tabular}{|llll|}
\hline & Aktif Çürük Var & Aktif Çürük Yok & Toplam \\
\hline Fırçalama evet & $18(\% 27.7)$ & $23(\% 35.4)$ & $41(\% 63.1)$ \\
\hline Fırçalama hayır & $14(\% 21.5)$ & $10(\% 15.4)$ & $24(\% 36.9)$ \\
\hline Toplam & $32(\% 49.2)$ & $33(\% 50.8)$ & $65(\% 100.0)$ \\
\hline
\end{tabular}

\begin{tabular}{|c|c|c|c|}
\hline & Çürük Pozitif & Çürük Negatif & Toplam \\
\hline GÖRH Evet & $14(\% 21.5)$ & $16(\% 24.6)$ & $30(\% 46.2)$ \\
\hline GÖRH Hayır & $18(\% 27.7)$ & $17(\% 26.2)$ & $35(\% 53.8)$ \\
\hline Toplam & $32(\% 49.2)$ & $33(\% 50.8)$ & 65 (\%100.0) \\
\hline
\end{tabular}

\section{TARTIŞMA}

Ağız-diş sağlığına doktorlar ve hastalar olarak yeteri kadar önem vermediğimiz bilinen bir gerçektir. Midedeki en küçük şikayette doğrudan gastroenteroloji bölümüne başvuran hastalarımızın, konu dişe geldiğinde aynı hassasiyeti göstermedikleri görülmektedir. Bu çalışmanın amacı GÖRH'nda diş çürüğü görülme oranı ve arasında olası bir ilişki olduğunun ortaya konulması iken; bir diğer amaç da hastalara sorulan her sorunun diş firçalama farkındalığını artırması idi. Bu konuda tıp doktorları olarak üzerimize düşen sorumlulukları yerine getirmemiz gerektiği görülmektedir. Bu çalışma ile üzerimizde düşen görevin sadece küçük bir kısmını yerine getirdiğimizi düşünüyoruz.

Çalışma bulguları değerlendirilirken diş fırçalama konusunda hastaların pratikte daha az diş fırçaladıklarını düşünmek gerekmektedir. Aksi takdirde bu yüksek çürük oranlarını dünya literatürü ile kıyaslamanın yanlış olacağı kanaatindeyiz. Her 5 hastanın birinde diş firçalarken görülen öğürme ve bulantı şikayetinin ise olması gerekenden fazla olduğu kanısındayı. Bu durumun diş firçalamama nedeni olarak hastalar tarafından kullanılması kuvvetli olmasa da üzerinde durulması gereken bir noktadır.

Bulgulara bakıldığında dispepsi şikayeti ile polikliniğe başvuranların kadın ağırlıklı olduğu görülmektedir. Kadın hastaların mide ağrısından daha fazla muzdarip oldukları anlaşılır bir durum iken, erkek hastalarda ise diş çürügünün bir miktar daha fazla görülmesi beklenen bir sonuçtur. Çalışmada ülseri olan hasta sayısının azlığı, diş çürüğü oranını artırmış gibi görünse de sağlıklı bir değerlendirme için yeterli değildir. Bunun için daha çok sayıda hasta ile geniş çalışmalar gerekmektedir. Gastrit çok saylda hastada mevcuttur ve bu yüzden bu çalışmada diş çürügü ile ilişkisi sorgulanmalıdır.

En dengeli hasta dağılımı GÖRH'nda görülmektedir. Bizim çalışmamızda da görüldüğü üzere GÖRH olanlar ile olmayanlar arasında çürük görülme oranının neredeyse eşit olduğu, bu hastalığın diş çürüğü ile anlamlı bir ilişkisi olmadığı yönünde bir kanıya varmamıza neden olmaktadır. Ancak GÖRH'nda birçok ağız bulgusunun görüldüğü bilinen bir gerçektir. GÖRH'nda diş erozyonlarının görülmesinin nedeni olarak gastrik asidik sekresyonların diş üzerindeki yıkıcı etkisi, azalmış yutma fonksiyonu ve diş üzerinde koruyucu etki gösteren azalmış tükrük salgısı gösterilebilir. Ancak diş çürügünde artış olmaması ise dikkate değer bir bulgudur. Literatürde de bu yönde çalışmalar mevcuttur. GÖRH'nda ağıda mevcut asidik pH; diş erozyonuna neden olurken, ağız florası üzerindeki öldürücü etkisinin diş çürüklerinin görülme oranını azalttığı yaygın bir kanıdır. Hastaların belirtiği gibi "benim midemde reflü var, dişim ondan çürüyor" yaklaşımının doğru olmadığı görülmekte ve bu bulgulardan önemli olanın diş fırçalama ve mekanik temizlik olduğu anlaşılmaktadir.

Buradan şöyle bir sonuç çıkarılabilir: diş fırçalamayan GÖRH'nda reflü tedavisi sonrası diş çürügü oranı artar mı? Bu ilginç soru üzerinde daha ileri çalışmalara ihtiyaç olduğu görülmektedir. Tıp doktoru olarak bizlere düşen, adeta her hastaya verilen proton pompa inhibitörünün yanında diş fırçası ve macunu da reçete edilmesidir. 


\section{KAYNAKLAR}

1- Song JY, Kim HH, Cho EJ, Kim TY. The relationship between gastroesophageal reflux disease and chronic periodontitis. Gut liver 2014;8:3540 .

2- Corrêa MC, Lerco MM, Cunha Mde L, Henry MA. Salivary parameters and teeth erosions in patients with gastroesophageal reflux disease. Arc Gastroenterol 2012;49:214-8.

3- Yoshikawa H1, Furuta K, Ueno M, et al. Oral symptoms including dental erosion in gastroesophageal reflux disease are associated with decreased salivary flow volume and swallowing function. J Gastroenterol 2012;47:412-20

4- Munoz JV, Herreros B, Sanchiz V, et al. Dental and periodontal lesions in patients with gastro-oesophageal reflux disease. Dig Liver Dis 2003;35:461-7.

5- Moazzez R, Anggiansah A, Bartlett DW. The association of acidic reflux above the upper eosophageal sphincter with palatal toot wear. Caries Res 2005;39:475-8
6- Dahshan Al, Patel H, Delaney J, et al. Gastroesophageal reflux disease and dental erosion in children. J Pediatr 2002;140:474-8.

7- Pace Fl, Pallotta S, Tonini M, et al. Systematic review: gastroesophageal reflux disease and dental lesions. Aliment Pharmacol Ther 2008;27:1179-86.

8- Wang GRl, Zhang H, Wang ZG, et al. Relationship between dental erosion and respiratory symptoms in patients with gastroesophageal reflux disease. J Dent 2010;38:892-8.

9- V Linnett V, Seow WK, Connor F, Shepherd R. Oral health of children with gastroesophageal reflux disease: a controlled study. Aust Dent J 2002;47:156-62.

10- Hom C, Vaezi MF. Extra-esophageal manifestations of gastroesophageal reflux disease: diagnosis and treatment. Drugs 2013;73:1281-95. 